Ann Epidemiol. 2011 August ; 21(8): . doi:10.1016/j.annepidem.2011.04.008.

\title{
BLACK PRETERM BIRTH RISK IN NON-BLACK NEIGHBORHOODS: EFFECTS OF HISPANIC, ASIAN, AND NON- HISPANIC WHITE ETHNIC DENSITIES
}

\author{
Susan M. Mason ${ }^{1,2}$, Jay S. Kaufman ${ }^{1,2,3}$, Julie L. Daniels ${ }^{1}$, Michael E. Emch ${ }^{2,4}$, Vijaya K. \\ Hogan $^{5}$, and David A. Savitz 6 \\ ${ }^{1}$ Department of Epidemiology, University of North Carolina, Chapel Hill, NC, USA \\ ${ }^{2}$ Carolina Population Center, University of North Carolina, Chapel Hill, NC, USA \\ ${ }^{3}$ Department of Epidemiology, Biostatistics, and Occupational Health, McGill University, Montreal, \\ Quebec, Canada \\ ${ }^{4}$ Department of Geography, University of North Carolina, Chapel Hill, NC, USA \\ ${ }^{5}$ Department of Maternal and Child Health, University of North Carolina, Chapel Hill, NC, USA \\ ${ }^{6}$ Departments of Community Health and Obstetrics and Gynecology, Brown University, \\ Providence, RI, USA
}

\begin{abstract}
Purpose-Studies of ethnic density and health in the United States have documented poorer health outcomes in black compared to non-black neighborhoods, but few studies have considered the identities of the non-black populations.
\end{abstract}

\begin{abstract}
Methods-New York City birth records from 1995 through 2003 and a spatial measure of ethnic density were used to examine preterm birth risks among non-Hispanic black women associated with non-Hispanic white, Hispanic, Asian, and non-Hispanic black neighborhood densities. Logistic regression models were used to estimate the effect on black preterm birth risks of replacing white neighbors with Hispanic, Asian, and black neighbors. Risk differences were computed for changes from the $10^{\text {th }}$ to the $90^{\text {th }}$ percentiles of ethnic density.
\end{abstract}

Results-Increasing Hispanic density was associated with reduced preterm birth risks among non-Hispanic black women, especially if the black women were foreign-born $(\mathrm{RD}=-19.1 \mathrm{per}$ 1,000 births; 95\% CI: -28.6, -9.5). Estimates for increasing Asian density were null. Increasing black density was associated with increasing black preterm birth risk, with a threshold at higher levels of black density.

Conclusions-The low risks of preterm birth among foreign-born non-Hispanic black women in majority-Hispanic neighborhoods may be related to protective psychosocial or nutritional factors in Hispanic neighborhoods.

(C) 2011 Elsevier Inc. All rights reserved.

Correspondence to: Susan M. Mason, Connor's Center for Women's Health and Gender Biology, Brigham \& Women's Hospital and Harvard Medical School, 1620 Tremont St, ${ }^{\text {rd }}$ Floor, Boston, MA 02120; smason4@ bics.bwh.harvard.edu; 617.525.9684 (phone); 617.525 .7746 (fax)

Publisher's Disclaimer: This is a PDF file of an unedited manuscript that has been accepted for publication. As a service to our customers we are providing this early version of the manuscript. The manuscript will undergo copyediting, typesetting, and review of the resulting proof before it is published in its final citable form. Please note that during the production process errors may be discovered which could affect the content, and all legal disclaimers that apply to the journal pertain. 


\section{Introduction}

Research on racial segregation in the United States (US) suggests that the health of black individuals is poorer in neighborhoods with a high proportion of other black residents (high black density) (1-10). Hypotheses for these effects are often framed as comparisons between black neighborhoods and white neighborhoods; for example, black neighborhoods may be harmful because they are poorer than white areas (11). But this comparison is largely theoretical, as most empirical studies have not compared black to white neighborhoods, but black to "non-black" neighborhoods. In many US cities, non-black neighborhoods include substantial numbers of Hispanic or Asian residents, and the particular ethnic composition of a non-black neighborhood may influence the pattern of neighborhood risk factors. For example, while white neighborhoods are typically wealthier than black neighborhoods (12), Hispanic neighborhoods are often poorer (13). Understanding how black population health varies with neighborhood ethnic densities may provide insight into the relative importance of material, social and nutritional neighborhood environments that differ with ethnic composition.

We know of only two published studies that have attempted to disentangle the effects of white and Hispanic neighborhoods on the health of their black residents. Inagami et al. found black residents of Hispanic neighborhoods to have higher age-adjusted mortality than those in white neighborhoods (13), consistent with the greater average poverty of Hispanic areas. In contrast, Masi et al. reported slightly lower odds of black preterm birth in Hispanic versus white neighborhoods in Chicago (14), an indication that there may be protective characteristics of Hispanic neighborhoods that buffer the harms of material deprivation. For instance, Hispanic neighborhoods are thought to facilitate health-positive behaviors among Hispanic residents (15), a protective milieu that might extend to members of other ethnic groups living nearby. We know of no studies that have examined black health outcomes in Asian neighborhoods.

We sought to understand how black population health varies by four neighborhood ethnic densities and the social and material environments they represent. We used geocoded New York City birth records and a census-based spatial measure of ethnic density to answer the following question: How does the risk of preterm birth among non-Hispanic black women differ if they have Hispanic, Asian, or non-Hispanic black neighbors rather than white neighbors? We focused on the health outcomes of non-Hispanic blacks because they appear to be uniquely disadvantaged by residential segregation (11). We chose preterm birth (PTB), or birth before the $37^{\text {th }}$ week of gestation, as the outcome because it is a leading cause of infant morbidity and mortality (16), is largely responsible for the substantial disparity in infant death rates between black and white populations in the US (17-19), and it appears to be sensitive to social and contextual stressors (20-25) that may arise from complex patterns of segregation.

\section{Methods}

\section{Data Sources and Management}

Geocoded New York City birth records provided outcome (gestational age), maternal ethnicity, maternal census tract of residence, and individual-level covariate data on all singleton births to women living in New York City from January 1, 1995 through December $31,2003(\mathrm{~N}=1,052,576)$. Of 935,825 births (89.5\%) with complete census tract and gestation length information, we identified 256,673 births to non-Hispanic black women for inclusion in our analysis. 
To compute ethnic densities, we downloaded Hispanic, Asian, non-Hispanic black, nonHispanic white, and total population counts for all 2,217 New York City census tracts from Summary File 1 of the 2000 US Census. Summary File 3 provided area-level covariates.

The Census Bureau split some 1990 census tracts to create two 2000 census tracts and merged other 1990 tract pairs to create single 2000 tracts (26). The New York City Department of Health and Mental Hygiene assigned 1990 tract numbers to births occurring in 1995-1999 and 2000 tract numbers to births occurring in 2000-2003. To create consistent tract numbers over time in the birth records, we gave 1990 tracts that were merged in 2000 their corresponding 2000 tract numbers. Likewise, we gave 2000 tracts that had split from 1990 tracts their "parent" 1990 tract numbers. We then merged the birth records with the census data in which the same changes had been made.

\section{Variables and Variable Construction}

We defined the outcome, preterm birth, as a live singleton birth with a clinical estimate of gestational age of greater than 20 but less than 37 weeks (16). The clinical estimate of gestational age has been found to be more accurate than estimates based on last menstrual period alone $(27,28)$.

We defined the exposure, neighborhood ethnic density, as the proportion of the population in a woman's area of residence self-reporting Hispanic, Asian, non-Hispanic black (henceforth referred to as "black"), or non-Hispanic white (henceforth referred to as "white") ethnic identity on the 2000 US Census. Following Reardon and Firebaugh $(29,30)$, we allowed the areas nearest a woman to contribute most to her experience of neighborhood-level ethnic density, with the influence of populations farther away decreasing in proportion to distance. We used the census tracts provided in the birth records to locate the mothers geographically; New York City census tracts are small, with a median area of 0.18 square kilometers, providing fairly precise locations. We estimated the distance from each woman's residence to other populations by computing the distances between geographically-weighted census tract centers (centroids) (31) in ArcGIS (ESRI).

To calculate the "proximity-weighted" Hispanic, Asian, black, or white density experienced by a black woman $(M)$ residing in census tract $J\left(\pi_{J M}\right)$, we multiplied the population of Hispanics, Asians, blacks, or whites $(N)$, respectively, in each census tract $K\left(x_{K N}\right)$ by a weight $\left(P_{J K}\right)$ representing the proximity of tracts $J$ and $K(29)$. We then summed these weighted ethnic populations and divided by total census tract populations $\left(x_{K}\right)$ that were weighted in the identical manner. This produced a weighted proportion, as shown below:

$$
\Pi_{J M}=\frac{\sum_{K}\left(x_{K N} \times p_{J K}\right)}{\sum_{K}\left(x_{K} \times p_{J K}\right)}
$$

The proximity weight $\left(p_{J K}\right)$, a "biweight kernel", allows census tract $K$ 's influence to decay in an approximately Gaussian manner with its distance from census tract $J(32)$ :

$$
p_{J K}=\left(1-\left(\frac{d_{J K}}{r}\right)^{2}\right)^{2} \quad \text { if } \quad d_{J K}<r, \text { else } \quad p_{J K}=0
$$

Where $d_{J K}$ is the distance between census tracts $J$ and $K$. Note that if $J=K$, then $d_{J K}=0$ and $p_{J K}=1$; that is, a census tract's own ethnic composition will have maximal influence on the 
estimated exposure of the residents of that census tract. The variable $r$ is the distance from census tract $J$ beyond which there is no influence on $J$ 's estimated ethnic density. The value of the radius was chosen based on the hypothesized area thought to meaningfully affect the environment of those living in census tract $J$. Lee and colleagues suggest a radius of 500 meters to approximate residential areas accessible by foot (32), which we considered to be an appropriate neighborhood definition for a densely populated urban area like New York City.

We included the following covariates in the adjusted models: maternal age (indicators for $<20,20-34$, and 35+ years), education taking age into account (indicators for $<12$ years and $<20$ years of age, <12 years and 20+ years of age, 12 years, 13-15 years, and 16+ years), nativity (US- or foreign-born), parity (indicators for 1, 2-5, and 6+ previous births), tobacco use (smoker or nonsmoker), prepregnancy weight (indicators for $<125,125-150$, and $>150$ pounds), prenatal care received in first 120 days of gestation (yes or no), and payment type (indicators for private insurance, Medicaid, or out-of-pocket). We did not include year of the child's birth as a covariate because it was unrelated to preterm birth in the study data.

Two contextual-level covariates, residential stability and neighborhood deprivation, were included in the adjusted models. Residential stability was defined as the percent of the neighborhood population residing in the same house from 1995 to 2000 . Neighborhood deprivation was represented using a standardized index arising from 17 tract-level census variables (Supplemental Table 1) that were summarized using principle components analysis as described by Messer et al (33). Both contextual-level covariates were proximity-weighted in the same manner as ethnic density and dichotomized at the birth records median. Adjustment for continuous versions of these covariates produced similar estimates.

\section{Data Analysis}

We used logistic regression to model the relationship between proximity-weighted Hispanic, Asian, black, and white ethnic densities and black PTB, with the Huber-White "sandwich" variance estimator to account for clustering at the tract level (34). We used marginal (population-averaged) models, which estimate effects for the entire population rather than for a specific census tract, making them more applicable for public health inference (35). These results were nearly identical to random-intercept model results.

We estimated crude associations by regressing the log odds of PTB among black women on Hispanic, Asian, black, and white ethnic densities in four separate models. We used continuous ethnic densities, because the log odds of black PTB was approximately linearly related to Hispanic, Asian, and white densities; a squared black density term was included in the black density model to accommodate a curvilinear exposure-outcome relationship. Using the logistic regression intercept and coefficients, we then computed risk differences (RDs) (36) with Stata's -nlcom- (College Station, TX), which uses the delta method to compute confidence intervals. Risk differences provide an estimate of the number of preterm births attributable to (or prevented by) residence in ethnically dense areas (assuming the modeled associations are valid and causal), and are therefore particularly well-suited for public health interpretation.

We calculated risk differences for a change from the $10^{\text {th }}$ to the $90^{\text {th }}$ percentiles of Hispanic, Asian, black, and white densities experienced by black women in their neighborhoods. For example, the $10^{\text {th }}$ percentile of Hispanic density corresponded to $5.2 \%$ Hispanic and the $90^{\text {th }}$ percentile corresponded to $61.9 \%$ Hispanic; that is, 10 percent of births to black women occurred in neighborhoods that were between $0 \%$ and $5.2 \%$ Hispanic while $90 \%$ occurred in neighborhoods that were between $0 \%$ and $61.9 \%$ Hispanic. Tenth and $90^{\text {th }}$ percentiles of Asian, non-Hispanic white, and non-Hispanic ethnic density are shown in Table 1. To aid in 
comparisons of ethnic density effects, we also computed risk differences for a change from $10 \%$ to $20 \%$ density for each group.

We considered maternal nativity (US- versus foreign-born) as a potential effect measure modifier, because immigrants' responses to their neighborhood may differ from that of their American-born counterparts; for example, neighborhood food environments may be more influential for immigrants, who are less likely than the US-born to have already adopted American dietary norms. We stratified crude models by maternal nativity, and chose to present stratified rather than combined results if the RDs for any ethnic density effect differed by more than 5 PTBs per 1,000 across strata.

Our adjusted model included continuous Hispanic, Asian, and black density variables, along with covariates. White density was excluded from the model to serve as the referent, so that those "unexposed" to Hispanics, Asians, or blacks were equivalent to those living in white neighborhoods. The adjusted model results may therefore be interpreted as the change in black preterm birth risk corresponding to the replacement of white neighbors with Hispanic, Asian, or black neighbors.

We also ran a reduced model without pre-pregnancy weight and early prenatal care. Almost $18 \%$ of records were missing data on one or both of these variables. We conducted a change-in-estimate analysis, and considered a change in the odds ratio of less than $10 \%$ minimal enough to prefer the increase in precision and generalizability gained by omitting these variables (37).

\section{Results}

On average, black births occurred to women residing in neighborhoods that were $58 \%$ black $(\mathrm{SD}=27), 26 \%$ Hispanic $(\mathrm{SD}=21), 9 \%$ white $(\mathrm{SD}=15)$, and $3 \%$ Asian $(\mathrm{SD}=6)$ (Table 1). The geographic distribution of black births in relation to neighborhood black, Hispanic, and Asian densities are shown in Supplemental Figures 1a-c.

The risk profiles of black women were similar across $90^{\text {th }}$-percentile Asian, white, and black neighborhoods(Supplemental Table 2). Black women residing in highly Hispanic neighborhoods were less educated and were more likely to receive late prenatal care, to be on Medicaid, and to report smoking during pregnancy than those in other neighborhoods. Hispanic neighborhoods were poorer than other areas (Supplemental Table 2).

Crude results suggested that Asian and white densities were associated with reduced black PTB risks, while Hispanic and black densities were associated with increased black PTB risks (Table 2). Stratification revealed substantial differences in ethnic density effects between US- and foreign-born non-Hispanic black women, however. In particular, while Hispanic density was associated with an increase of 8.2 PTBs per 1,000 births (95\% CI 3.3, 13.0) among US-born non-Hispanic black women, among the $44 \%$ of non-Hispanic black women born outside the US, Hispanic density appeared to offer a substantial protective effect, with a reduction in PTB risk of -19.3 per 1,000 (95\% CI: $-24.3,-14.4$ ) (Table 2, Figure 1). Effect estimates for other ethnic densities also differed across nativity strata, although less dramatically. Asian density appeared to be protective among US-born black women only. Non-Hispanic black density was associated with an increase of 13.0 PTBs per 1,000 births (95\% CI: 8.2, 17.8) among foreign-born black women, but with a much smaller increase in risk ( $\mathrm{RD}=3.8$ per 1,$000 ; 95 \% \mathrm{CI}:-1.3,8.8)$ among the US-born.

The protective effect of Hispanic density on foreign-born non-Hispanic black PTB risks was unchanged by covariate adjustment (adjusted $\mathrm{RD}=-19.1$ per 1,$000 ; 95 \% \mathrm{CI}:-28.6,-9.5$ ) (Table 2, Figure 1). Adjustment moved Asian density effect estimates toward the null. 
Adjustment did not change non-Hispanic black density effects for US-born blacks, but changed them substantially for foreign-born blacks. While the crude results suggested that non-Hispanic black density increased PTB risks among foreign-born blacks, adjusted results indicated a slight and imprecise protective effect (adjusted RD $=-5.3 ; 95 \%$ CI: $-15.2,4.6$ ). This change from the crude to adjusted estimates appears to be driven largely by confounding by Hispanic density, which is inversely correlated with black density; that is, in crude models - without adjustment for Hispanic density - black PTB risks increase with increasing black density because of associated decreases in protective Hispanic density. When Hispanic density is held constant in adjusted models, non-Hispanic black density is no longer associated with increases in foreign-born black PTB risks.

Using a comparison of $20 \%$ to $10 \%$ density, Hispanic density was associated with a reduction in PTBs to foreign-born black women of -3.6 per 1,000 births (95\% CI: -5.5 , -1.7) (Table 3). A curvilinear relationship between black density and black PTB, such that risk increases occur largely at the lower end of the black density range, resulted in similar estimates of black density effects on US-born black PTB risks using $90^{\text {th }}$-to- $10^{\text {th }}$ percentile ( $89 \%$ versus $18 \%$ black) and 20\%-to-10\% contrasts (Table 3). Foreign-born black women had a slight increase in PTB risk associated with a $10 \%$ to $20 \%$ increase in black density, but an apparent decrease in risk associated with a $10^{\text {th }}$ to $90^{\text {th }}$ percentile increase.

Over 1,000 births to black mothers occurred in neighborhoods that were $40 \%$ Asian or more, and we calculated the risk difference for a change in Asian density from 0\% to $40 \%$ to see whether an association would emerge in the higher-density neighborhoods. The risk difference $(-3.1$ per $1,000,95 \%$ CI: $-14.9,8.7)$ indicated a slight protective effect of Asian density, but the estimate was very imprecise.

The two most frequently missing variables - prenatal care and pre-pregnancy weight - were not included in the final models, because the change in the odds ratio resulting from their exclusion was less than $10 \%$ for all estimates. See Supplemental Table 3 for fully adjusted risk differences.

We conducted several supplemental analyses. First, we re-ran models with spontaneous preterm birth, using linked hospital discharge diagnosis and procedure codes to identify and exclude medically-indicated preterm births (births subsequent to any surgical or medical induction of labor and births subsequent to pre-labor cesarean sections)(38). Second, models were run among primiparous women to remove any influence of repeat births to the same woman. Third, models were re-run with very preterm birth (VPTB, birth before 33 completed weeks of gestational age) as the outcome. The overall pattern of results remained the same in the supplemental analyses (Supplemental Table 4). The results for VPTB show an even more dramatic relative decrease associated with high Hispanic density among foreign-born non-Hispanic black women ( $\mathrm{RD}=-5.7$ per 1000; 95\% CI: $-10.4,-1.1)$, corresponding to a reduction in risk from $2.1 \%$ in less Hispanic neighborhoods to $1.5 \%$ in more Hispanic neighborhoods.

To assess the potential influence of gestational age misclassification, we re-ran models with preterm low birth weight (gestational age $<37$ weeks and birth weight $<2500 \mathrm{~g}$ ) and very low birth weight (birth weight $<1500 \mathrm{~g}$ ), two highly specific subsets of preterm birth that are unlikely to be misclassified. We found reductions in risk associated with Hispanic neighborhoods similar to the main analyses, indicating that our findings are not attributable to preterm birth misclassification.

Finally, because Caribbean immigrants make up the majority of both the New York City Hispanic population and the foreign-born non-Hispanic black mothers in the birth records, we considered the possibility that a shared sense of Caribbean culture or ethnic identity 
makes Hispanic neighborhoods beneficial specifically to Caribbean black immigrants. We categorized foreign-born non-Hispanic black women into African and Caribbean immigrant groups, based on self-reported country of birth, expecting to find a protective effect in the Caribbean group alone. Both Africans and Caribbeans appeared to benefit from residence in Hispanic neighborhoods, however (RD for Caribbeans $=-10.2 ; 95 \%$ CI: $-22.1,1.6$ and RD for Africans $=-15.4 ; 95 \% \mathrm{CI}-34.5,3.7)$, indicating that Hispanic neighborhoods may afford protections to black immigrant residents from various regions.

\section{Discussion}

This investigation was motivated by the possibility that black health outcomes vary not only with neighborhood-level black density, but are also differentially responsive to the presence of specific non-black ethnic groups and the social and material environments they represent. The findings of this study suggest that, at least in New York City, non-Hispanic blacks who are foreign-born fare better with Hispanic than white neighbors. Given the high degree of poverty associated with Hispanic neighborhoods relative to white ones, this result indicates that there may be favorable social or lifestyle environments in Hispanic neighborhoods.

Notably, the reduction in black PTB risk associated with residence in Hispanic neighborhoods was not experienced by US-born black women. Foreign-born women, who are likely to be in the process of assimilating new cultural norms, may be more influenced than their US-born counterparts by elements of Hispanic neighborhoods, such as availability of Hispanic foods, that are hypothesized to be protective (15).

This study was limited by lack of information on maternal assimilation beyond maternal place of birth. More sophisticated measures of assimilation would allow for a more nuanced understanding of the differential effect of Hispanic density observed across maternal nativity categories.

The null association found between Asian density and black preterm birth may stem from the narrow range of Asian density for which the risk difference was calculated ( $0 \%$ to $8 \%$ ). Though the risk difference corresponding to a greater increase (0\% to 40\%) in Asian density suggests a protective role of Asian density, the imprecision of this estimate indicates that Black-Asian neighborhood interactions may still be too rare in New York City to get a useful estimate their effects.

Our study is one of only a handful of analyses to examine black health across multiple ethnic contexts. In addition, we employed a spatial measure of neighborhood-level ethnic density in order to address the documented limitations of non-spatial segregation measures (39). While our data precluded exploration of hypothesized mechanisms linking ethnic density and health, and the extent to which causality can be inferred from our results is limited by the cross-sectional nature of the analysis and by the potential for differential selection into neighborhoods by preterm birth risk, our findings are robust to a variety of outcome, population, and model specifications and indicate, in particular, that further investigations of black immigrant health outcomes in Hispanic areas may be fruitful.

Future studies may build on these results by investigating specific environmental and psychosocial variables in Hispanic neighborhoods. In addition, areas where black-Asian interactions may be more common, such as Los Angeles, provide a promising context for understanding the effects of an even more diverse set of neighborhood environments. Such an understanding will highlight social and contextual factors of particular importance for birth outcomes and provide information on how shifts in residential patterns might alleviate or exacerbate the burden of preterm birth in the black community. 


\section{Supplementary Material}

Refer to Web version on PubMed Central for supplementary material.

\section{Acknowledgments}

This work was supported by Centers for Disease Control and Prevention Public Health Research Dissertation Grant 1R36DP001849-01.

\section{Abbreviations}

$\begin{array}{ll}\text { RD } & \text { risk difference } \\ \text { CI } & \text { confidence interval } \\ \text { PTB } & \text { preterm birth } \\ \text { US } & \text { United States }\end{array}$

\section{References}

1. Jackson SA, Anderson RT, Johnson NJ, et al. The relation of residential segregation to all-cause mortality: a study in black and white. Am J Public Health. 2000; 90:615-7. [PubMed: 10754978]

2. Grady SC. Racial disparities in low birthweight and the contribution of residential segregation: a multilevel analysis. Soc Sci Med. 2006; 63:3013-29. [PubMed: 16996670]

3. Morenoff JD. Neighborhood Mechanisms and the Spatial Dynamics of Birth Weight. The American Journal of Sociology. 2003; 108:976-1017.

4. Huie SAB, Hummer RA, Rogers RG. Individual and Contextual Risks of Death among Race and Ethnic Groups in the United States. J Health Soc Behav. 2002; 43:359-81. [PubMed: 12467258]

5. LeClere FB, Rogers RG, Peters KD. Ethnicity and Mortality in the United States: Individual and Community Correlates. Social Forces. 1997; 76:169-98.

6. McCord C, Freeman HP. Excess mortality in Harlem. N Engl J Med. 1990; 322:173-7. [PubMed: 2294438]

7. White K, Borrell LN. Racial/ethnic neighborhood concentration and self-reported health in New York City. Ethn Dis. 2006; 16:900-8. [PubMed: 17061744]

8. Acevedo-Garcia D. Zip code-level risk factors for tuberculosis: neighborhood environment and residential segregation in New Jersey, 1985-1992. Am J Public Health. 2001; 91:734-41. [PubMed: 11344881]

9. Mason SM, Messer LC, Laraia BA, et al. Segregation and preterm birth: the effects of neighborhood racial composition in North Carolina. Health Place. 2009; 15:1-9. [PubMed: 18359264]

10. Yankauer A. The relationship of fetal and infant mortality to residential segregation: an inquiry into social epidemiology. American Sociological Review. 1950; 15:644-8.

11. Williams DR, Collins C. Racial residential segregation: a fundamental cause of racial disparities in health. Public Health Rep. 2001; 116:404-16. [PubMed: 12042604]

12. Laraia BA, Messer L, Kaufman JS, et al. Direct observation of neighborhood attributes in an urban area of the US south: characterizing the social context of pregnancy. Int J Health Geogr. 2006; 5:11. [PubMed: 16545132]

13. Inagami S, Borrell LN, Wong MD, et al. Residential segregation and Latino, black and white mortality in New York City. J Urban Health. 2006; 83:406-20. [PubMed: 16739044]

14. Masi CM, Hawkley LC, Harry Piotrowski Z, et al. Neighborhood economic disadvantage, violent crime, group density, and pregnancy outcomes in a diverse, urban population. Social Science \& Medicine. 2007; 65:2440-57. [PubMed: 17765371]

15. Reyes-Ortiz CA, Ju H, Eschbach K, et al. Neighbourhood ethnic composition and diet among Mexican-Americans. Public Health Nutr. 2009:1-9. [PubMed: 19087373] 
16. Berkowitz GS, Papiernik E. Epidemiology of preterm birth. Epidemiol Rev. 1993; 15:414-43. [PubMed: 8174665]

17. Hogue CJ, Hargraves MA. Preterm birth in the African-American community. Semin Perinatol. 1995; 19:255-62. [PubMed: 8560290]

18. Hogue CJ, Vasquez C. Toward a strategic approach for reducing disparities in infant mortality. Am J Public Health. 2002; 92:552-6. [PubMed: 11919050]

19. Fiscella K. Racial disparity in infant and maternal mortality: confluence of infection, and microvascular dysfunction. Matern Child Health J. 2004; 8:45-54. [PubMed: 15198171]

20. Dole N, Savitz DA, Siega-Riz AM, et al. Psychosocial factors and preterm birth among African American and White women in central North Carolina. Am J Public Health. 2004; 94:1358-65. [PubMed: 15284044]

21. Lu MC, Chen B. Racial and ethnic disparities in preterm birth: the role of stressful life events. Am J Obstet Gynecol. 2004; 191:691-9. [PubMed: 15467527]

22. Collins JW Jr. David RJ, Symons R, et al. Low-income African-American mothers' perception of exposure to racial discrimination and infant birth weight. Epidemiology. 2000; 11:337-9. [PubMed: 10784254]

23. Rosenberg L, Palmer JR, Wise LA, et al. Perceptions of racial discrimination and the risk of preterm birth. Epidemiology. 2002; 13:646-52. [PubMed: 12410005]

24. Rini CK, Dunkel-Schetter C, Wadhwa PD, et al. Psychological adaptation and birth outcomes: the role of personal resources, stress, and sociocultural context in pregnancy. Health Psychol. 1999; 18:333-45. [PubMed: 10431934]

25. Messer LC, Kaufman JS, Dole N, et al. Neighborhood crime, deprivation, and preterm birth. Ann Epidemiol. 2006; 16:455-62. [PubMed: 16290179]

26. New York City Department of City Planning. [2001;Accessed 9/20/2010] Table G-1: New York City 1990 Census Tracts with Boundary/Number Changes for 2000 Census. http://wwwnycgov/ $\mathrm{html} / \mathrm{dcp} / \mathrm{pdf} / \mathrm{census} / \mathrm{g} 1 \mathrm{pdf}$

27. Ananth CV. Menstrual versus clinical estimate of gestational age dating in the United States: temporal trends and variability in indices of perinatal outcomes. Paediatr Perinat Epidemiol. 2007; 21(Suppl 2):22-30. [PubMed: 17803615]

28. Joseph KS, Huang L, Liu S, et al. Reconciling the high rates of preterm and postterm birth in the United States. Obstet Gynecol. 2007; 109:813-22. [PubMed: 17400841]

29. Reardon SF, Firebaugh G. Response: Segregation and Social Distance: A Generalized Approach to Segregation Measurement. Sociological Methodology. 2002; 32:85-101.

30. Reardon SF, Matthews SA, O'Sullivan D, et al. The Geographic Scale of Metropolitan Racial Segregation. Demography. 2008; 45:489-514. [PubMed: 18939658]

31. Jenness Enterprises. [Accessed 9/20/2010] Polygon Center of Mass. http://wwwjennessentcom/ arcview/centermasshtm

32. Lee BA, Reardon SF, Firebaugh G, et al. Beyond the Census Tract: Patterns and Determinants of Racial Residential Segregation at Multiple Scales. American Sociological Review. 2006; 73:76691.

33. Messer LC, Laraia BA, Kaufman JS, et al. The development of a standardized neighborhood deprivation index. J Urban Health. 2006; 83:1041-62. [PubMed: 17031568]

34. Williams RL. A note on robust variance estimation for cluster-correlated data. Biometrics. 2000; 56:645-6. [PubMed: 10877330]

35. Hubbard AE, Ahern J, Fleischer NL, et al. To GEE or Not to GEE: Comparing Population Average and Mixed Models for Estimating the Associations Between Neighborhood Risk Factors and Health. Epidemiology. 2010; 21:467-74. [PubMed: 20220526]

36. Austin PC. Absolute risk reductions, relative risks, relative risk reductions, and numbers needed to treat can be obtained from a logistic regression model. J Clin Epidemiol. 2009; 63:2-6. [PubMed: 19230611]

37. Mickey RM, Greenland S. The impact of confounder selection criteria on effect estimation. Am J Epidemiol. 1989; 129:125-37. [PubMed: 2910056] 
38. Stein CR, Savitz DA, Janevic T, et al. Maternal ethnic ancestry and adverse perinatal outcomes in New York City. Am J Obstet Gynecol. 2009; 201:584 e1-9. [PubMed: 19729145]

39. Reardon, SF. A conceptual framework for measuring segregation and its association with population outcomes. In: Oakes, MJ.; Kaufman, JS., editors. Methods in Social Epidemiology. Jossey-Bass Publishing; 2006. 


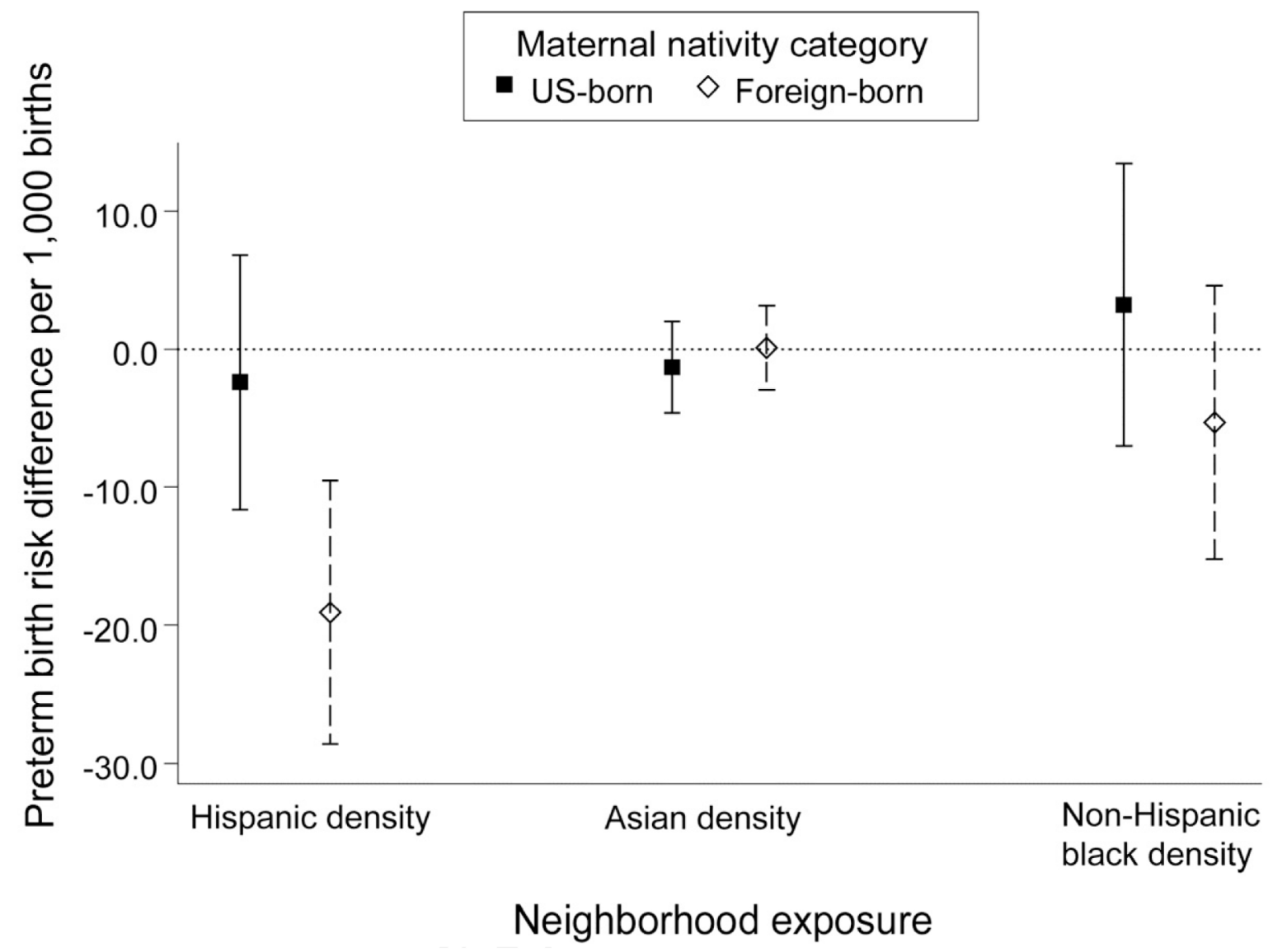

Figure 1.

Preterm birth risk differences per 1,000 births, with $95 \%$ confidence intervals, among nonHispanic black women associated with increase from $10^{\text {th }}$ to $90^{\text {th }}$ percentiles of neighborhood non-Hispanic black density ( $17.8 \%$ to $88.9 \%$ black), Hispanic density (5.2\% to $61.9 \%$ Hispanic), and Asian density (0.3\% to $8.1 \%$ Asian). Risk differences were calculated for women aged 20-34 who were high school educated, had 2-5 previous live births, were nonsmokers, were on Medicaid, and resided in a more stable, poorer, and whiter neighborhood. 
Table 1

Distribution of births to non-Hispanic black mothers across exposure and covariate levels: New York City birth records, 1995-2003

\begin{tabular}{|c|c|c|c|}
\hline Continuous variables & \multicolumn{2}{|c|}{ Mean (SD) } & $\begin{array}{c}\text { Median } \\
\left(10^{\text {th }}, 90^{\text {th }}\right. \\
\text { percentile })\end{array}$ \\
\hline Hispanic density ${ }^{a}(\%)$ & \multicolumn{2}{|c|}{$26.0(21.3)$} & $18.7(5.2,61.9)$ \\
\hline $\operatorname{Asian}_{\text {density }}{ }^{a}(\%)$ & \multicolumn{2}{|c|}{$3.3(5.9)$} & $1.2(0.3,8.1)$ \\
\hline White density ${ }^{a}(\%)$ & \multicolumn{2}{|c|}{$8.8(15.0)$} & $2.2(0.6,23.6)$ \\
\hline Black density $^{a}(\%)$ & \multicolumn{2}{|c|}{$58.1(27.2)$} & $64.1(17.9,88.9)$ \\
\hline Categorical variables & $\mathrm{N}$ & $\%$ & $\%$ РTB \\
\hline \multicolumn{4}{|l|}{ Age (years) } \\
\hline$<20$ & 27,714 & $10.8 \%$ & $10.8 \%$ \\
\hline $20-34$ & 183,203 & $71.4 \%$ & $10.2 \%$ \\
\hline $35+$ & 45,756 & $17.8 \%$ & $13.5 \%$ \\
\hline \multicolumn{4}{|c|}{ Maternal education (years) } \\
\hline$<12$, age $<20$ & 18,130 & $7.2 \%$ & $11.1 \%$ \\
\hline$\langle 12$, age $\rangle=20$ & 46,091 & $18.2 \%$ & $12.0 \%$ \\
\hline 12 & 93,299 & $36.9 \%$ & $11.0 \%$ \\
\hline $13-15$ & 63,635 & $25.2 \%$ & $10.1 \%$ \\
\hline $16+$ & 31,678 & $12.5 \%$ & $9.5 \%$ \\
\hline \multicolumn{4}{|l|}{ Previous births } \\
\hline 1 & 107,920 & $42.1 \%$ & $10.5 \%$ \\
\hline $2-5$ & 144,273 & $56.2 \%$ & $10.9 \%$ \\
\hline $6+$ & 4,469 & $1.7 \%$ & $17.3 \%$ \\
\hline \multicolumn{4}{|c|}{ Prepregnancy weight (pounds) $b$} \\
\hline$<125$ & 44,777 & $19.0 \%$ & $12.0 \%$ \\
\hline $125-150$ & 86,615 & $36.7 \%$ & $10.3 \%$ \\
\hline$>150$ & 104,617 & $44.3 \%$ & $10.0 \%$ \\
\hline \multicolumn{4}{|l|}{ Tobacco use } \\
\hline Nonsmoker & 240,397 & $94.2 \%$ & $10.3 \%$ \\
\hline Smoker & 14,690 & $5.8 \%$ & $18.6 \%$ \\
\hline \multicolumn{4}{|c|}{ Late or no prenatal care ${ }^{a}$} \\
\hline No & 169,652 & $75.0 \%$ & $10.1 \%$ \\
\hline Yes & 56,563 & $25.0 \%$ & $11.0 \%$ \\
\hline \multicolumn{4}{|l|}{ Payment for delivery } \\
\hline Private insurance & 86,774 & $34.6 \%$ & $9.9 \%$ \\
\hline Medicaid & 155,211 & $61.8 \%$ & $11.0 \%$ \\
\hline self pay & 9,095 & $3.6 \%$ & $15.9 \%$ \\
\hline
\end{tabular}




\begin{tabular}{cccc}
\hline Continuous variables & Mean (SD) & $\begin{array}{c}\text { Median } \\
\mathbf{( 1 0}^{\text {th }}, \mathbf{9 0}^{\text {th }} \\
\text { percentile) }\end{array}$ \\
\hline us-born & 141,969 & $55.7 \%$ & $11.9 \%$ \\
$\begin{array}{l}\text { Foreign-born } \\
\text { Residential stability }\end{array}$ & 112,966 & $44.3 \%$ & $9.5 \%$ \\
Less stable & & & \\
More stable & 102,521 & $39.9 \%$ & $10.4 \%$ \\
Neighborhood deprivation & 154,139 & $60.1 \%$ & $11.1 \%$ \\
Richer & & & $10.0 \%$ \\
Poorer & 93,087 & $36.3 \%$ & $11.3 \%$ \\
\hline
\end{tabular}

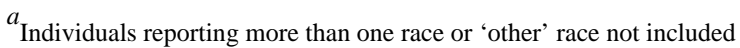

${ }^{b}$ Variables were missing for less than $4 \%$ of observations, with the exception of prepregnancy weight $(8.1 \%$ missing) and prenatal care (11.9\% missing) 


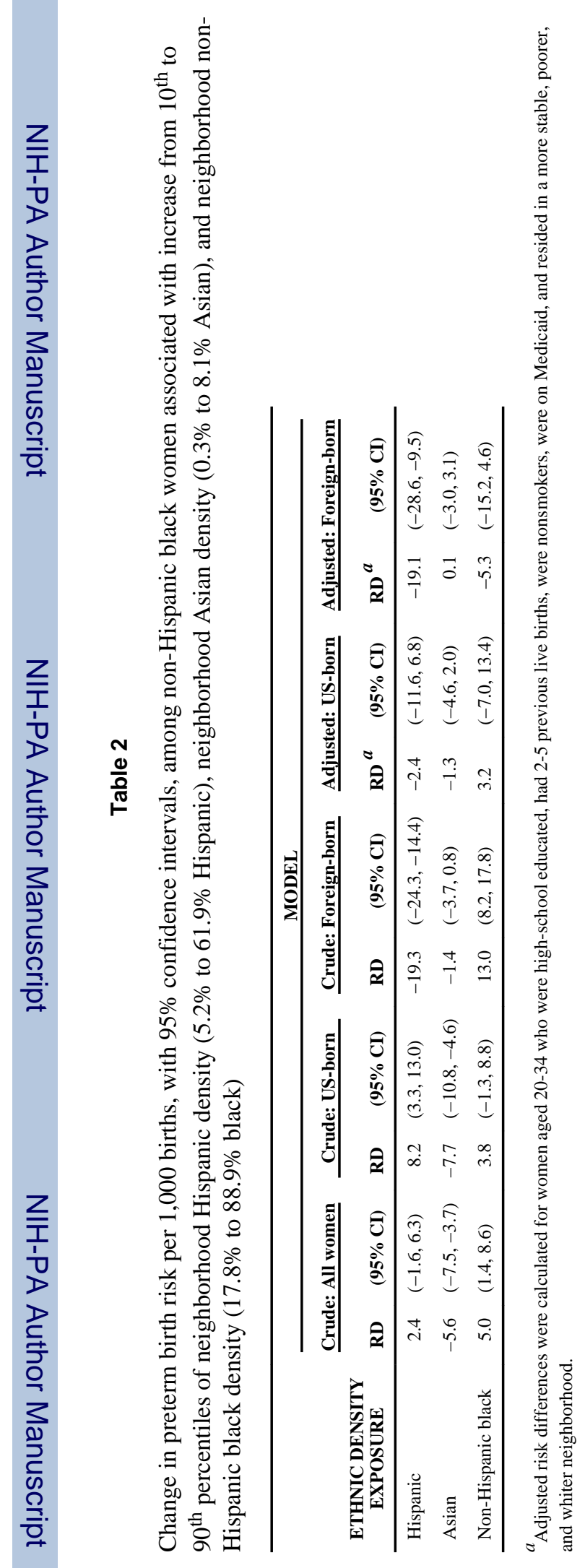

Ann Epidemiol. Author manuscript; available in PMC 2014 January 07. 


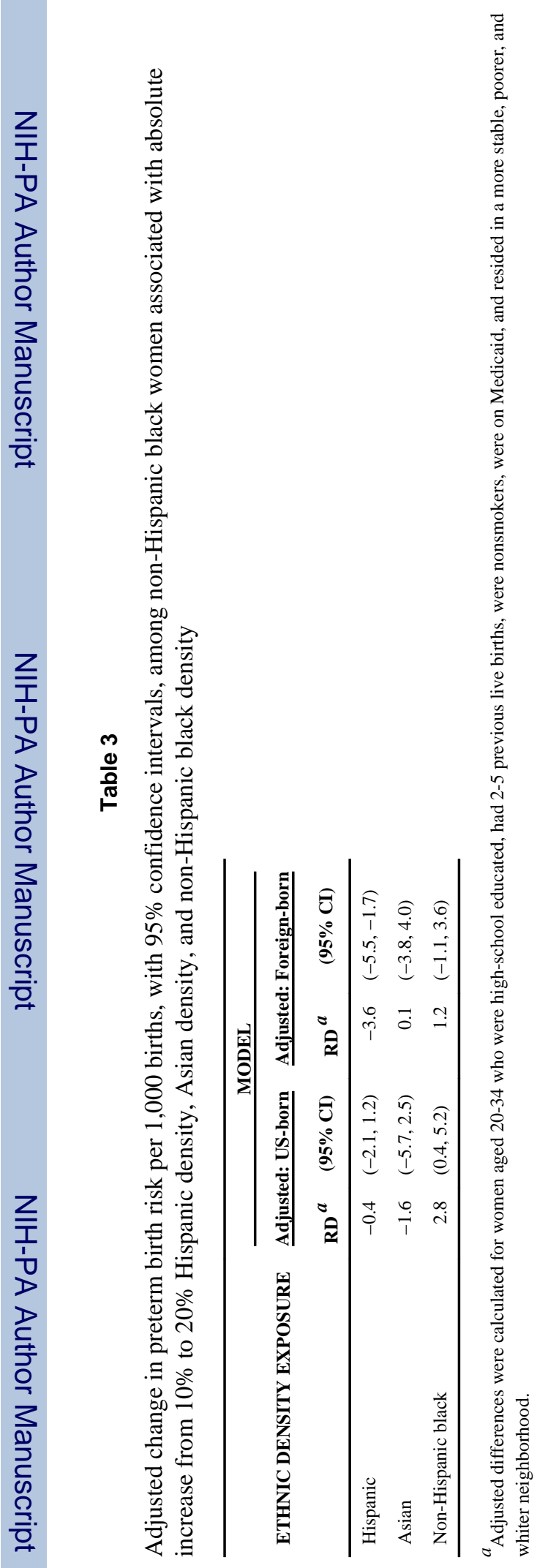

Ann Epidemiol. Author manuscript; available in PMC 2014 January 07. 